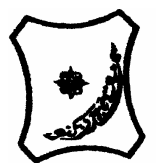

Bayero Journal of Pure and Applied Sciences, 6(2): 89 - 92

Received: July 2013

Accepted: December 2013

ISSN $2006-6996$

\title{
EVALUATION OF THE PROBABILITY OF USING TOTAL LYMPHOCYTE COUNT AS AN ALTERNATIVE TO CD4 COUNT IN INITIATION OF ART
}

\author{
${ }^{*}$ Tijjani, J. ${ }^{1}$ and Okafor, P.A. ${ }^{2}$ \\ ${ }^{1}$ Laboratory Department, Infectious Diseases Hospital Kano, Nigeria \\ ${ }^{2}$ Department Of Clinical Chemistry, School of Medical Laboratory Science, Ahmadu Bello University Teaching \\ Hospital, Zaria, Kaduna State, Nigeria \\ *Correspondence author: jamilutijjani234@yahoo.com
}

\begin{abstract}
Measurement of $\mathrm{CD4}^{+} \mathrm{T}$ cell count in the diagnosis of HIV in a resource-constrain settings is often difficult due to high cost of equipments, reagents, and demand for trained personnel. There is need for relatively cost effective technique with good Prognosis for Human Immunodeficiency Virus (HIV) infection. Two hundred and fourty four (244) HIV seropositive (tests) and fifty (50) HIV seronegative individuals (controls) were analyzed for CD4 count and TLC. The result of the study was analyzed using SPSS 14, the mean \pm SEM $930 \pm 43 \mathrm{cells} / \mu \mathrm{l}$ (CD4 count) and $2026 \pm 75$

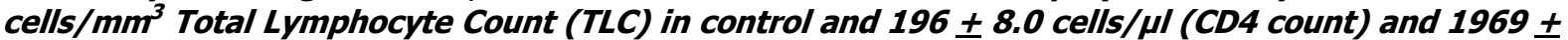
$66 \mathrm{cells} / \mathrm{mm}^{3}$ (TLC) in Test group were obtained. There was significant difference between the values of CD4 count recorded in Test $(196 \pm 8.0 \mathrm{cells} / \mu)$ when compared with the value recorded in Control $(930 \pm 43 \mathrm{cells} / \mu(\mathrm{l})(p<0.01)$, but there was no significant difference in the values of TLC recorded in Test (1969 \pm 66 cells $\left./ \mathrm{mm}^{3}\right)$ when compared with the values recorded in the control $\left(2026 \pm 75 \mathrm{cells} / \mathrm{mm}^{3}\right)(p<0.01)$. This is due to the fact that CD4+T /ymphocyte are specifically targeted by HIV which results in linear reduction in CD4 count not the whole population of TIymphocytes and B-/ymphocytes. A spearman's correlation study was done between the CD4 counts and $T L C$, indicated a slightly positive correlation ( $r=0.586)$ among the test individuals and strong positive correlation in the control $(r=0.739)$. It could be concluded that total lymphocyte count can not be used alone as an alternative to CD4 count in initiating ART, but in conjunction with clinical sign and symptoms.
\end{abstract}

Keywords: Human immunodeficiency virus, CD4 count, Total lymphocyte count, and Antiretroviral therapy.

\section{INTRODUCTION}

According to the united nations program on HIV/AIDS (UNAIDS), more than 45 million people have been infected with the human immunodeficiency virus (HIV) since the first case was described in 1981 . Over $90 \%$ of HIV infected people live in developing countries. The AIDS epidemic has resulted in a tremendous cost in terms of loss of lives and life-quality worldwide, especially in Africa, where $70 \%$ of deaths from HIV-1 infection have occurred (UNAID and WHO 2007). There is an emerging consensus that the HIV epidemic in the developing world requires treatment with antiretroviral drugs (Gange et al., 2003). In wellresourced settings, the decision to initiate ART is based predominantly on the presence of HIV-related symptoms and on CD4+ T-cell count (Badri and Wood 2003). Absolute CD4+ T-cell counts and CD4+ percentages have constituted the mainstay criteria for monitoring progression in HIV-1 infected patients. CD4+ T-cell counts $<200$ cell $/ \mathrm{mm} 3$ or a CD4+ percentage $<20 \%$ is associated with an increased risk for Pneumocystis jiroveci pneumonia or infection with other opportunistic pathogens (Badri and Wood 2003). Monitoring individuals with HIV infection/AIDS requires the use of expensive tools, which are not readily available in resource-limited settings (Akinola et al., 2004). The identification of laboratory tests that help the clinician to predict progression is useful not only to monitor the patients' disease evolution but also to define the right time to initiate treatment (WHO 2005). In 2003, WHO recommended the use of absolute lymphocyte count as an alternative marker when a CD4+ cell count is not available or is not affordable. And recommended that a total lymphocyte count of $\leq 1200$ lymphocytes/mm3 can be substituted for the CD4 count when the later is unavailable and HIV-related symptoms existed. One challenge for using TLC for predicting the disease stage is that it does not linearly decrease over time during HIV infection, but rather there is a period of stability, followed by a faster decay that precedes clinically-defined AIDS (Gange et al., 2003).

This research was design to assess the level of CD4 cell count and total lymphocyte count in the HIV positive (tests) and HIV negative (controls), also to assess the relationship between CD4 cell count and TLC and to compare our findings with those obtainable in other part of the world.

\section{MATERIALS AND METHODS}

The study was conducted at laboratory department of Infectious Diseases Hospital (I.D.H.) Kano. Two hundred and fourty four (244) newly diagnosed HIV seropositive (tests) individuals (112 males and 132 females) distributed among 4 age groups (20-30: 89, 31-40: 96, 41-50: 43, 51-60: 16) and fifty (50) apparently healthy 
HIV seronegative (controls) individuals (21 male and 39 females) distributed among 4 age groups (20-30: 34, 31-40: 10, 41-50: 4, 51-60: 2) were enrolled in this study. A $5 \mathrm{ml}$ whole blood sample from each patient was collected in EDTA vacutainer tubes in the morning between 8:00am to 10:00am.

The Total CD4+ T Lymphocytes was determined using an automated flow cytometer (Partec Cyflow Counter 060727120, Germany). The blood samples were processed and analyzed within six hours from the time samples were collected. And the total lymphocyte were obtained from Full Blood Count results, using an Automated Hematology Analyzer (Sysmex KX-21N, Sysmex Corporation. Results obtained were analyzed using SPSS 14.0 for windows.

\section{RESULTS}

The results obtained in this study are expressed as mean \pm SEM (Standard error of mean) for the control and the test individuals respectively. These are presented in Tables $1-4$ and Figures 1 and 2.

Table 1: CD4 and Total Lymphocyte Count (TLC) in Test and control

\begin{tabular}{llll}
\hline Sample & $\mathbf{n}$ & CD4 Count & Total Lymphocytes \\
\hline Control & 50 & $930 \pm 43$ & $2026 \pm 75$ \\
Test & 244 & $196 \pm 8.0$ & $1969 \pm 66$ \\
\hline
\end{tabular}

It can be seen that there was significant difference between the values of CD4 count recorded in Test $(196 \pm 8.0$ cells $/ \mu)$ when compared with the value recorded in Control $(930 \pm 43$ cells $/ \mu l)(p<0.01)$. IBut there was no significant difference in the values of TLC recorded in Test $\left(1969 \pm 66\right.$ cells $\left./ \mathrm{mm}^{3}\right)$ when compared with the values recorded in the control $\left(2026 \pm 75\right.$ cells $\left./ \mathrm{mm}^{3}\right)(p<0.01)$.

Table 2: CD4 count and Total Lymphocyte Count (TLC) in Females Test and Control subjects

\begin{tabular}{lllc}
\hline Sample & $\mathbf{n}$ & CD4 Count & Total Lymphocytes \\
\hline Control & 29 & $1031 \pm 60$ & $2165 \pm 99$ \\
Test & 132 & $219 \pm 12$ & $1760 \pm 70$ \\
\hline
\end{tabular}

Table 3: CD4 count and Total Lymphocyte Count (TLC) in Males Test and Control subjects

\begin{tabular}{llll}
\hline Sample & n & CD4 Count & Total Lymphocytes \\
\hline Control & 21 & $790 \pm 46$ & $1833 \pm 104$ \\
Test & 112 & $170 \pm 10$ & $1743 \pm 96$ \\
\hline
\end{tabular}

Table 4: Spearman's Correlation Coefficient ( $r$ ) of CD4 Count and TLC in Test and Control HIV Seronegative HIV Seropositive

\begin{tabular}{lcccc} 
& $\mathbf{n}$ & $\mathbf{r}$ & $\mathbf{n}$ & \\
\hline Male \& Female & 50 & 0.739 & 244 & 0.586 \\
Male & 21 & 0.764 & 112 & 0.611 \\
Female & 39 & 0.693 & 132 & 0.569 \\
$20-30$ yrs & 34 & 0.747 & 89 & 0.593 \\
$31-40$ yrs & 10 & 0.839 & 96 & 0.625 \\
$41-50$ yrs & 4 & 0.400 & 43 & 0.464 \\
$51-60$ yrs & 2 & 1.0 & 16 & 0.696 \\
\hline
\end{tabular}




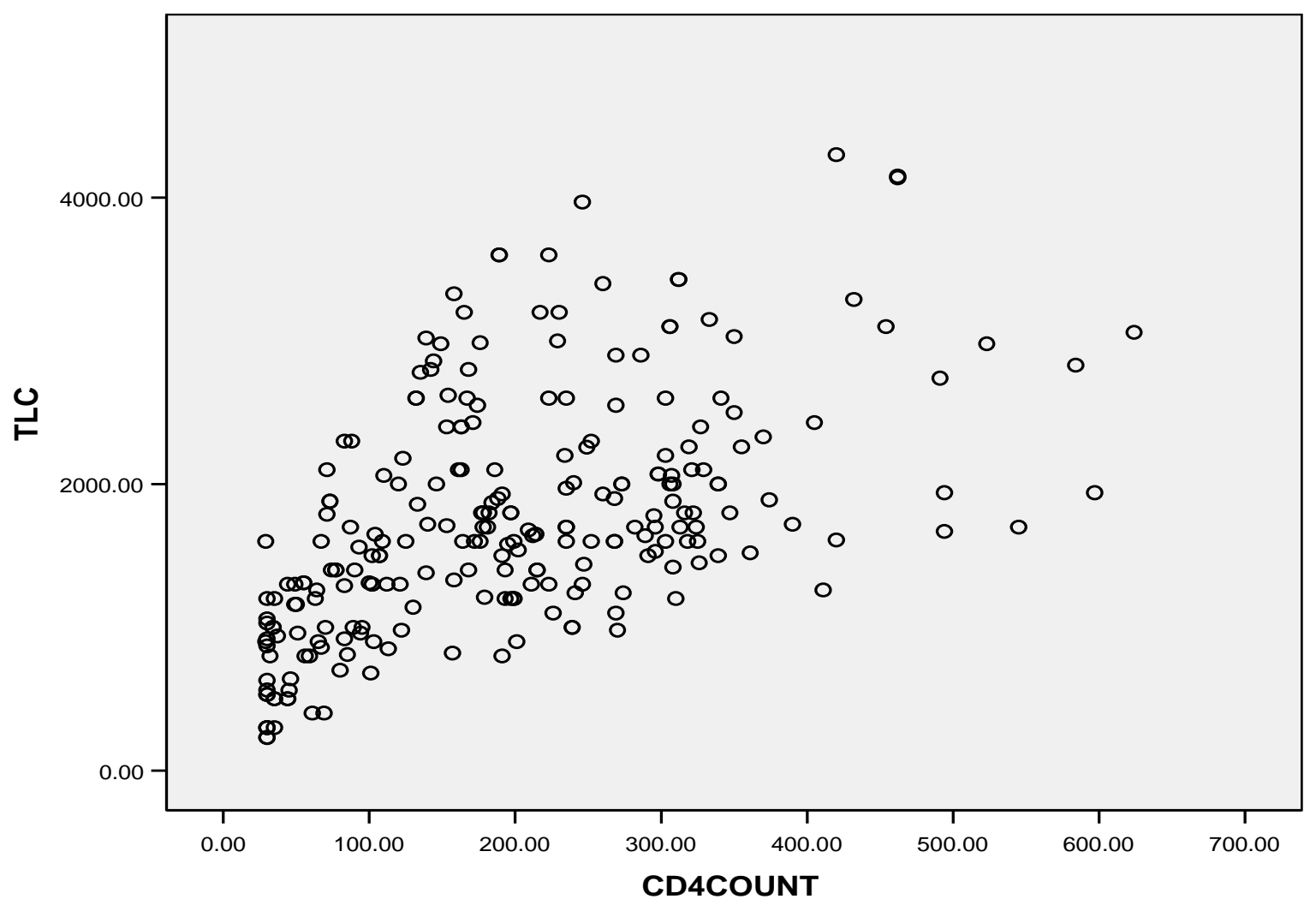

Figure 1: Scatter Graph of CD4 Count and TLC in Test subjects.

A scatter graph of spearman's correlation study of CD4 count and TLC in test subjects indicating a slightly positive correlation $(r=0.586)$.

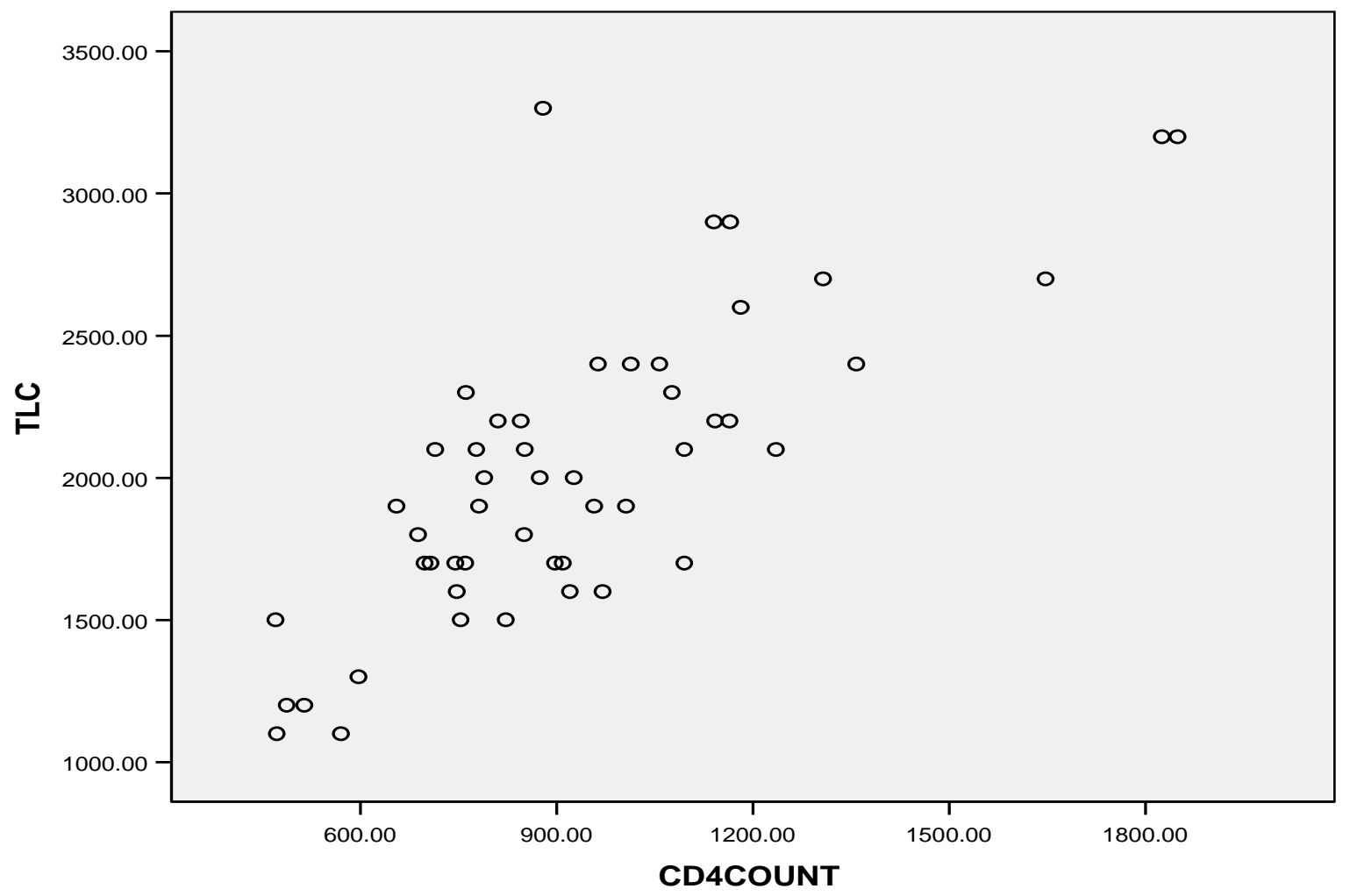

Figure 2: Scatter Graph of CD4 Count and TLC in Control subjects.

A scatter graph of spearman's correlation study of CD4 count and TLC in control subjects indicating strong positive correlation $(r=0.739)$. 


\section{DISCUSSION}

From our result, we recorded a mean of $930 \pm 43$ cells $/ \mu \mathrm{l}$ (CD4 count), $2026 \pm 75$ cells $/ \mathrm{mm}^{3}$ (TLC) in control and $196 \pm 8.0$ cells/ $/ \mu$ l (CD4 count) and 1969 \pm 66 cells $/ \mathrm{mm}^{3}$ (TLC) in Test group. It can be seen that there was significant difference between the values of CD4 count recorded in Test $(196 \pm 8.0$ cells $/ \mu$ ) when compared with the value recorded in Control $(930 \pm 43$ cells $/ \mu l)(p<0.01)$. But there was no significant difference in the values of TLC values recorded in Test $\left(1969 \pm 66\right.$ cells $\left./ \mathrm{mm}^{3}\right)$ when compared with the values recorded in the control $\left(2026 \pm 75\right.$ cells $\left./ \mathrm{mm}^{3}\right)(p<0.01)$. This was due to the facts that CD4+T lymphocyte are specifically targeted by HIV which results in linear reduction in CD4 count. A spearman's correlation study was done between the CD4 counts and TLC, there was a slightly positive correlation $(r=0.586)$ in the test and strong positive correlation in control $(r=0.739)$.

Considering the above resuls this work agrees with the findings of Gange et al., (2003), Johnson et al., (2009) and Akinola et al., (2004): Gange et al (2003) reported that total lymphocyte count does not linearly decrease over time during HIV infection, but rather there is period of stability

\section{REFERENCES}

Akinola, O. O., Adediran, I. A., Onayemi, O. et al, (2004): The search for a predictor of CD4 cell count continues: Total lymphocyte count is not a substitute for CD4 cell count in the management of HIV infected individuals in a resource-limited setting. Clin Infect Dis, 39: 579-81

Badri, M., Wood, R. (2003): Usefulness of total lymphocyte count in monitoring highly active antiretroviral therapy in resource-limited settings. AIDS; 17(4):541-5.

Blatt, S. P, Lucey, C. R., Butzin, C. A., Hendrix, C. W., Lucey, D. R. (1993): Total lymphocyte count as a predictor of absolute CD4+ count and CD4+ percentage in HIV-infected persons. JAMA, 269: 622-626.

Fournier, A. M., Sosenko, J. M. (1992): The relationship of total lymphocyte count to CD4 lymphocyte counts in patients infected with Human Immunodeficiency Virus. $\mathrm{Am} \mathrm{J} \mathrm{Med}$ SCi ;304(2): 79-82.

Gange, S. J. L. B., Phair, J., Riddler, S. A. et al (2003): Rapid declines in total lymphocyte count and hemoglobin in HIV infection begin at CD4 lymphocyte counts that justify antiretroviral therapy. AIDS;17:119-31.

Johnson, O. O., Benjamin, B. S., Daniel, K. et al., (2009): Total Lymphocyte Count and World Health Organization Pediatric Clinical Stage as Markers to Assess Need to initiate Antiretroviral Therapy Among Human Immunodeficiency Virus-Infected Children in followed by a faster decay that precedes clinically defined AIDS. Johnson et a.I, (2009) reported that low absolute lymphocyte count does not correlate with the severe immune suppression based on CD4 cell count, it also does not improve ability to identify children in need of ART. Akinola et al., (2004) and Vand Der Ryst et al., (1998) found that TLC is not a good predictor of the CD4+ T-cell count.

This work disagree with the work of Fournier and Sosenko (1992) and Blatt et al., (1993). Fournier and sosenko (1992) stated that total lymphocyte count has a clinical utility as a predictor of AIDS stage. Blatt et al., (1993) reported that TLC was a useful indicator of significant immune suppression.

\section{COCLUSION}

Total lymphocyte count could not be used alone as an alternative to CD4 count in initiating ART, but in conjunction with clinical sign and symptoms.

\section{RECOMMENDATION}

It could therefore be recommended that larger number of patients be used and other factors that affect immune system like nutritional status and presence or absence of coinfection be considered.

Moshi, Northern Tanzania. The Pediatric Infectious Disease Journal: Volume 28 - Issue 6 - pp 493-497.

UNAIDS, (2009): UNAID Press Office The Global Facts and Figures: Global HIV Epidemiology. web March 2010, at http//www.communication@unaids.org

UNAIDS, WHO (2007): AIDS epidemic update. Geneva: web 26 april, 2010, at http://data.unaids.org/pub/EPISlides/2007/2 007_epiupdate_en.pdf

Van Der Ryste, K. M., Joubert, G., Steyn, M. et al, (1998): Correlation among total lymphocyte count. absolute CD4+ count. and CD4 percentage in a group of HIV-1 infected South African patients. I Acquir Immune Defic Syndr and Human Retrovirology,19(3): 238-44.

WHO (2005): Antiretroviral Drugs for the Treatment of HIV Infection in Infants and Children in Resource-Limited Settings: Recommendations for a Public Health Approach, Geneva.

WHO (2003): Scaling up antiretroviral therapy in resource-limited settings: treatment guidelines for a public health approach. Geneva.

WHO (2004): Scaling up antiretroviral therapy in resource-limited settings: Guidelines for a Public Health Approach-2003 Revision. Geneva: web May 23 2010, at http://www.who.int/hiv/pub/prev_care/en/ar vrevision2003en.pdf. 